\title{
Developmental Febrile Seizures Modulate Hippocampal Gene Expression of Hyperpolarization-Activated Channels in an Isoform- and Cell-Specific Manner
}

\author{
Amy Brewster, ${ }^{1 *}$ Roland A. Bender, ${ }^{1,2 *}$ Yuncai Chen, ${ }^{2}$ Celine Dube, ${ }^{1}$ Mariam Eghbal-Ahmadi, ${ }^{2}$ and \\ Tallie Z. Baram ${ }^{1,2,3}$ \\ Departments of ${ }^{1}$ Anatomy/Neurobiology, ${ }^{2}$ Pediatrics, and ${ }^{3}$ Neurology, University of California at Irvine, Irvine, \\ California 92697-4475
}

\begin{abstract}
Febrile seizures, in addition to being the most common seizure type of the developing human, may contribute to the generation of subsequent limbic epilepsy. Our previous work has demonstrated that prolonged experimental febrile seizures in the immature rat model increased hippocampal excitability long term, enhancing susceptibility to future seizures. The mechanisms for these profound proepileptogenic changes did not require cell death and were associated with long-term slowed kinetics of the hyperpolarization-activated depolarizing current $\left(I_{H}\right)$. Here we show that these seizures modulate the expression of genes encoding this current, the hyperpolarization-activated, cyclic nucleotide-gated channels (HCNs): In CA1 neurons expressing multiple $\mathrm{HCN}$ isoforms, the seizures induced a coordinated reduction of HCN1 mRNA and enhancement of HCN2 expression, thus altering the neuronal HCN phenotype. The seizure-
\end{abstract}

Seizures induced by fever (febrile seizures) occur in 1 of 7 to 1 of 30 infants and children worldwide, thus constituting the most common seizure type of the developing brain (Hauser, 1994). However, the mechanisms for the generation of these intense bouts of synchronized abnormal neuronal activity remain unclear, and importantly, the consequences of these seizures are incompletely understood. Conflicting human studies have implicated prolonged $(>15 \mathrm{~min})$ febrile seizures as potential key determinants of the generation of spontaneous hippocampal/ limbic seizures (temporal lobe epilepsy) later in life (Shinnar, 1998; Cendes and Andermann, 2002). However, the direct causal relationship of prolonged febrile seizures to this common epilepsy, and the mechanisms by which these early life seizures might be proepileptogenic, have not been resolved.

Using an appropriate aged model of prolonged febrile seizures, we have previously demonstrated profound and long-term enhancement of hippocampal excitability, with increased susceptibility to future seizures (Dubé et al., 2000). The mechanisms for these proepileptogenic changes did not require cell death

\footnotetext{
Received Jan. 6, 2002; revised March 12, 2002; accepted March 15, 2002.

This work was supported by National Institutes of Health Grants NS 35439, NS 28912 (T.Z.B.), and NS28912-S1 (A.B.), and by a postdoctoral research fellowship from the Epilepsy Foundation of America (R.A.B.). We thank Dr. B. Santoro for critical and helpful discussions, Drs. A. Ludwig, F. Hofmann, and M. Biel for the HCN probes, and M. Hinojosa for excellent editorial help.

*A.B. and R.A.B. contributed equally to this work.

Correspondence should be addressed to Dr. Tallie Z. Baram, Departments of Anatomy/Neurobiology and Pediatrics, University of California at Irvine, Med. Sci. I, 4475; UCI, Irvine, CA 92697-4475. E-mail: tallie@uci.edu.

Copyright (C) 2002 Society for Neuroscience $0270-6474 / 02 / 224591-09 \$ 15.00 / 0$
}

induced augmentation of $\mathrm{HCN} 2$ expression involved $\mathrm{CA} 3$ in addition to CA1, whereas for HCN4, mRNA expression was not changed by the seizures in either hippocampal region. This isoform- and region-specific transcriptional regulation of the $\mathrm{HCNs}$ required neuronal activity rather than hyperthermia alone, correlated with seizure duration, and favored the formation of slow-kinetics HCN2-encoded channels. In summary, these data demonstrate a novel, activity-dependent transcriptional regulation of $\mathrm{HCN}$ molecules by developmental seizures. These changes result in long-lasting alteration of the HCN phenotype of specific hippocampal neuronal populations, with profound consequences on the excitability of the hippocampal network.

Key words: hippocampus; development; febrile seizures; epilepsy; channels; hyperpolarization; HCN; neuroplasticity
(Toth et al., 1998; Bender and Baram, 2002) and were associated with potentiated perisomatic inhibition of hippocampal pyramidal cells and altered properties of the hyperpolarizationactivated depolarizing current $\left(I_{\mathrm{H}}\right)$ (Chen et al., 1999; K. Chen et al., 2001). This current, encoded by a family of genes [hyperpolarization-activated, cyclic nucleotide-gated channels (HCNs), see below], undergoes short-term regulation by cAMP (DiFrancesco and Tortora, 1991; Waigner et al., 2001). However, the febrile seizure-induced changes were both cAMP independent and long lasting (weeks to months) (K. Chen et al., 2001). Therefore, we conducted a series of experiments to test the hypothesis that these seizures lead to transcriptional regulation of $\mathrm{HCN}$ subunit isoforms, thus modifying the HCN phenotype of individual neurons long term.

HCNs mediate the hyperpolarization-activated $\left(I_{\mathrm{H}}\right)$ currents in the heart (DiFrancesco, 1993) and brain (Pape, 1996). These channels participate in regulating neuronal membrane potential (Lupica et al., 2001) and contribute critically to pacemaker activity, promoting synchronization of neuronal networks such as those in the thalamus and hippocampus (Pape, 1996; Santoro and Tibbs, 1999). As mentioned above, short-term modulation of $\mathrm{HCN}$ gating involves the binding of cAMP to the $\mathrm{C}$ terminal intracellular domain of the channel (Waigner et al., 2001). This subunit-specific mechanism permits rapid and short-term modulation of channel kinetics and activation-potential curves by synaptic and metabolic alterations of cellular cAMP (DiFrancesco and Tortora, 1991; Waigner et al., 2001).

HCNs are encoded by four characterized genes (Santoro et al., 1997, 1998; Gauss et al., 1998; Ludwig et al., 1998; Ishii et al., 
Table 1. Parameters and procedures for developmental seizures

\begin{tabular}{|c|c|c|c|c|c|}
\hline Group/parameter & $n$ & $\begin{array}{l}\text { Maximal } \\
\text { temperature }\left({ }^{\circ} \mathrm{C}\right)\end{array}$ & $\begin{array}{l}\text { Threshold } \\
\text { temperature }\left({ }^{\circ} \mathrm{C}\right)\end{array}$ & $\begin{array}{l}\text { Hyperthermia } \\
\text { duration (min) }\end{array}$ & $\begin{array}{l}\text { Seizure } \\
\text { duration }(\mathrm{min})\end{array}$ \\
\hline Experimental febrile seizures & 37 & $42.5 \pm 0.06$ & $40.7 \pm 0.15$ & $28.2 \pm 0.29$ & $22.8 \pm 0.33$ \\
\hline Hyperthermia alone & 19 & $42.4 \pm 0.09$ & - & $28.8 \pm 0.23$ & - \\
\hline Kainate-induced seizures & 8 & - & - & - & $173 \pm 50.9$ \\
\hline
\end{tabular}

1999; Monteggia et al., 2000), three of which (HCN1, HCN2, and HCN4) are expressed in rodent hippocampus (Moosmang et al., 1999; Santoro et al., 2000; Bender et al., 2001). Four HCN molecules of the same isoform type assemble to form homomeric HCNs. Because the isoform composition of these channels determines their physiological responses (S. Chen et al., 2001; Ulens and Tytgat, 2001), we reasoned that long-term alteration in HCN function may be attributable to modulation of $\mathrm{HCN}$ isoform expression by prolonged experimental febrile seizures.

Therefore, we first analyzed HCN mRNA and protein expression in rat hippocampus during the developmental age of febrile seizures and demonstrated regional and neuronal specificity for the expression of each HCN isoform. We established the coexpression of multiple HCNs in individual pyramidal cells and interneurons in CA1 and CA3 and proceeded to query whether the developmental febrile seizures regulated $\mathrm{HCN}$ isoform gene expression patterns. We then examined whether the mechanisms of such novel transcriptional regulation required intense activation of the hippocampal circuit (seizures) or might be attributable to the hyperthermia procedure itself. Finally, we determined the specificity and duration of these seizure-induced effects for each hippocampal-expressed $\mathrm{HCN}$ isoform.

\section{MATERIALS AND METHODS}

Generation of developmental seizures. Prolonged experimental febrile seizures were provoked as described previously (Toth et al., 1998; Chen et al., 1999; Dubé et al., 2000; Dubé, 2002), using immature rats during a hippocampal and cortical developmental age generally equivalent to that of the human infant and young child (Gottlieb et al., 1977; Herschkowitz et al., 1997). Hyperthermia (i.e., increased body and brain temperatures) was induced in 10- to 11-d-old Sprague Dawley rats using a warmed air stream directed $\sim 50 \mathrm{~cm}$ above the animals. Core temperatures were measured before hyperthermia induction, at 2 min intervals, and at the onset of hyperthermia-provoked seizures. These core temperatures have been correlated with brain temperatures under the precise experimental conditions used (Dubé, 2002). After $30 \mathrm{~min}$ of hyperthermia, calibrated to evoke $\sim 20 \mathrm{~min}$ of seizures (Table 1 ), animals were moved to a cool surface and then returned to their mothers. Hyperthermic controls were generated by subjecting littermates to the same hyperthermia procedure, but blocking the resulting seizures using the rapid and short acting barbiturate pentobarbital. The dose used $(30 \mathrm{mg} / \mathrm{kg}$, i.p.) was sufficient to prevent the hyperthermia-induced electrographic and behavioral seizures yet led to a short (typically $<1 \mathrm{hr}$ ) effect (e.g., sedation). Little evidence of dehydration was observed from this mild procedure $(<3 \%$ loss of body weight), and animals rapidly regained normal activity, including suckling (Dubé, 2002). An additional, normothermic control group was used as well.

Longer hippocampal seizures (lasting $\sim 180 \mathrm{~min}$ ) (Table 1) were induced in immature rats of the same age using the glutamate receptor agonist kainate, as described previously (Brunson et al., 1998). The dose used $(1.2 \mathrm{mg} / \mathrm{kg}$, i.p.) resulted in limbic hyperexcitability and in electrographic as well as behavioral seizures (Tremblay et al., 1984; Brunson et al., 1998) (Table 1).

To confirm the hippocampal origin of the behavioral seizures provoked by these procedures and to correlate behavioral with electrophysiological parameters, a separate group of rats was implanted with bipolar electrodes directed to the dorsal hippocampus as described previously (Brunson et al., 1998; Dubé et al., 2000). Hippocampal EEGs were recorded from these behaving animals before and during hyperthermia- or kainate-induced seizures and also served to confirm the activityblocking actions of pentobarbital. The brains of these animals were not harvested for analysis.

Tissue harvesting and processing. Animals ( $n=119$ total; 7-10 per group per procedure per age) were killed as described for each procedure. For radioactive in situ hybridization (ISH), animals were decapitated within minutes of the investigators' entering the animal facility, to minimize potential effects of stress-related neuronal activation (Baram and Hatalski, 1998). Brains were rapidly dissected on powdered dry ice and stored and handled as described previously (Eghbal-Ahmadi et al., 1999), with the exception that cryostat sections $(20 \mu \mathrm{m})$ were divided into anatomically matched series. For immunocytochemistry (ICC), fluorescent in situ hybridization, and combined analyses, animals were perfused and brains were handled as described previously (Bender et al., 2001; Y. Chen et al., 2001).

ICC. HCN ICC was performed on free-floating sections $(20 \mu \mathrm{m})$ using standard avidin-biotin complex methods as described previously (Y. Chen et al., 2001). Briefly, after several washes with 0.01 M PBS containing $0.3 \%$ Triton X-100 (PBS-T), pH 7.4, sections were treated for $30 \mathrm{~min}$ in $0.3 \% \mathrm{H}_{2} \mathrm{O}_{2} / \mathrm{PBS}$, followed by blockade of nonspecific sites with $2 \%$ normal goat serum in PBS for $30 \mathrm{~min}$. After rinsing, sections were incubated for $36 \mathrm{hr}$ at $4^{\circ} \mathrm{C}$ with rabbit anti-HCN1 or anti-HCN2 serum (1:4000 and 1:2000, respectively; Chemicon, Temecula, CA) in PBS containing $1 \%$ bovine serum albumin (BSA) and washed three times in PBS-T for $5 \mathrm{~min}$. Sections were incubated in biotinylated goat-anti-rabbit IgG (1:200; Vector Laboratories, Burlingame, CA) in PBS for $1 \mathrm{hr}$ at room temperature. After washing three times for $5 \mathrm{~min}$, sections were incubated in the avidin-biotin-peroxidase complex solution $(1: 100$; Vector Laboratories) for $2 \mathrm{hr}$ and then rinsed three times for $5 \mathrm{~min}$; the reaction product was visualized by incubating the sections in $0.04 \%$ $3,3^{\prime}$-diaminobenzidine containing $0.01 \% \quad \mathrm{H}_{2} \mathrm{O}_{2}$. The specificity of the $\mathrm{HCN}$ antisera was evaluated in several ways. First, elimination of the primary antibody resulted in a loss of all signal. In addition, the concordance of the immunoreactivity of each HCN isoform with the specific cell populations expressing the cognate mRNA in immature rats was determined (Bender et al., 2001). Finally, the distribution of the immunoreactivity was also compared with previous publications (Santoro and Tibbs, 1999). Thus, no HCN1 immunoreactivity was evident in the thalamus, whereas strong $\mathrm{HCN} 2$ signal was observed in the thalamic nucleus reticularis, shown to express this subunit isoform exclusively (Santoro et al., 2000; data not shown).

Fluorescent ISH. To examine for the presence of a specific HCN isoform in individual, neurochemically defined neurons, fluorescent ISH of HCN subunit/isoforms was performed, modified from the published nonradioactive ISH procedures (Bender et al., 2001; Y. Chen et al., 2001). Briefly, antisense and sense riboprobes were generated from transcription vectors containing cDNA of mouse HCN1 (corresponding to amino acids 636-722), HCN2 (322-481), or HCN4 (400-690) and labeled with digoxigenin (DIG). ISH was performed on free-floating sections $(20 \mu \mathrm{m})$ that were washed in $2 \times$ SSC for $30 \mathrm{~min}$ and then subjected to an additional $30 \mathrm{~min}$ incubation in a solution composed of $2 \times \mathrm{SSC} /$ prehybridization solution (1:1). Prehybridization took place for $1 \mathrm{hr}$ at $65^{\circ} \mathrm{C}$ in a humid chamber. For hybridization, digoxigenin-labeled RNA probes were added (final concentration, $\sim 10 \mathrm{ng} / \mathrm{ml}$ prehybridization buffer) and sections were incubated at $65^{\circ} \mathrm{C}$ for $16 \mathrm{hr}$. After hybridization, sections were subjected to washes of increasing stringency, consisting of $2 \times \mathrm{SSC}$ at room temperature (twice for $15 \mathrm{~min}$ ), $50 \%$ formamide $/ 2 \times \mathrm{SSC}$ at $70^{\circ} \mathrm{C}$ for $60 \mathrm{~min}, 50 \%$ formamide $/ 0.1 \times \mathrm{SSC}$ at $70^{\circ} \mathrm{C}$ for $60 \mathrm{~min}$, and $0.1 \times \mathrm{SSC}$ at $70^{\circ} \mathrm{C}$ for $30 \mathrm{~min}$. Hybrid molecules were detected using a tyramide signal amplification technique (Hunyady et al., 1996) and a fluorescent reporter (Cy3 or FITC). Briefly, after several washes with $0.01 \mathrm{M}$ PBS-T, pH 7.4, sections were treated for $30 \mathrm{~min}$ in $0.3 \% \mathrm{H}_{2} \mathrm{O}_{2} / \mathrm{PBS}$, followed by blockade of nonspecific sites with $2 \%$ normal goat serum in PBS for $30 \mathrm{~min}$. After rinsing, sections were 
incubated overnight at $4^{\circ} \mathrm{C}$ with anti-DIG mouse antibody (1:1000; Roche, Indianapolis, IN) in PBS containing 1\% BSA and then washed in PBS-T three times for $5 \mathrm{~min}$. Sections were incubated in freshly prepared $0.5 \%$ blocking buffer (Perkin-Elmer, Boston, MA) for $30 \mathrm{~min}$ at room temperature, followed by incubation with horseradish peroxidase (HRP)-conjugated anti-mouse IgG (1:500; Molecular Probes, Eugene, $\mathrm{OR}$ ) in $0.5 \%$ blocking buffer for $2 \mathrm{hr}$. After washing (three times for 5 min), sections were incubated in the dark for no longer than 10 min with tyramide conjugated to the fluorophore (Perkin-Elmer), diluted 1:75 in amplification buffer, and washed with PBS-T. The specificity of the probes and of the amplified signal was verified by substituting labeled sense probe for the antisense probe and by omitting either the antisense probe or the HRP-conjugated anti-mouse $\operatorname{IgG}$, respectively. No labeling was observed under these conditions (see also Bender et al., 2001).

Fluorescent ISH combined with fluorescent ICC. To determine whether multiple HCN isoforms were colocalized in an individual neuron and to establish the neurochemical identity of neurons expressing HCNs, the ISH procedure described above was combined with ICC. Specifically, free-floating sections $(20 \mu \mathrm{m})$ were first processed for HCN2 or HCN1 fluorescent ISH according to the protocol described above. Sections were rinsed and incubated overnight at $4^{\circ} \mathrm{C}$ with rabbit anti-HCN1 antiserum (1:2000) or mouse anti-parvalbumin monoclonal antibody (1:50,000; Sigma, St. Louis, MO). Immunoreactivity was visualized using goat anti-rabbit (or anti-mouse) IgG conjugated to Alexa Fluor 568 (1:400; Molecular Probes) in PBS containing 1\% BSA. To evaluate the possibility of altered sensitivity or specificity attributable to combined ISH-ICC, sections processed for this combined procedure were compared with matched sections processed for ICC or ISH alone. No differences in intensity, distribution, or number of labeled cells were observed.

For all methods using fluorophore, sections were initially viewed using a Nikon (Tokyo, Japan) Eclipse E400 epifluorescence microscope equipped with fluorescein, rhodamine, and 4',6'-diamidino-2-phenylindoleFITC-tetramethylrhodamine isothiocyanate filter sets. Images were obtained using an Olympus Fluoview confocal microscope (FV300-IX; Olympus Optical, Tokyo, Japan) and acquired in Adobe Photoshop format (Adobe Systems, San Jose, CA).

Semiquantitative ISH. Relative quantitative analysis of HCN mRNA levels was accomplished using radioactively labeled ISH probes and calibration standards, under conditions of signal linearity (EghbalAhmadi et al., 1999; Brunson et al., 2001). Briefly, the ISH was performed as described above and in previous publications (Bender et al., 2001), with the exception that probes were radiolabeled, requiring minor procedural modifications: the ISH was performed on slide-mounted frozen sections $(20 \mu \mathrm{m})$ as detailed previously (Eghbal-Ahmadi et al., 1999). To ascertain the isoform specificity of the hybridization, the reaction was performed at $55^{\circ} \mathrm{C}$ followed by washes, the most stringent of which was with $0.03 \times \mathrm{SSC}$ at $62^{\circ} \mathrm{C}$ for $60 \mathrm{~min}$.

Data acquisition and analysis. Data acquisition and analysis were performed as described previously (Eghbal-Ahmadi et al., 1999; Brunson et al., 2001) on sections run concurrently, and always without knowledge of treatment. The significance level for $t$ tests and ANOVA was set at 0.05 , and data are presented as means \pm SEs.

\section{RESULTS}

\section{HCN mRNA and protein are widely and selectively expressed in immature rat hippocampus in an age-specific pattern}

Of the four characterized HCN subunit genes, HCN1, HCN2, and HCN4 mRNAs are expressed in the developing rat hippocampal formation as early as postnatal day 2 (P2) (Bender et al., 2001). During postnatal development and particularly during the period when experimental febrile seizures influence hippocampal excitability ( $\sim \mathrm{P} 10-\mathrm{P} 20)$, both the mRNA and protein of these three HCN subunits are expressed in isoform-specific patterns involving select hippocampal regions and cell populations (see Figs. 1, 2, 4) (Bender et al., 2001). As shown in these figures, excellent correlation exists between the expression of these channel molecules at the mRNA and protein levels. In general, expression of HCN1 is higher than those of HCN2 and HCN4 (Figs. $1, A$ vs $D, 4, A$ vs $B, C$ ). More specifically, high protein expression of HCN1 occurs throughout the CA1 pyrami- dal cell layer (Fig. 1A,B), including pyramidal cells as well as parvalbumin-expressing, basket cell-type interneurons (Figs. $1 B$, arrows and arrowheads, respectively, $2 E, F)$. This correlates well with HCN1 mRNA expression patterns at the layer/regional and the single-cell resolutions (see Figs. 4 and $2 A, C$, respectively). In addition, expression of $\mathrm{HCN} 1$ protein in the dendritic fields of CA1 pyramidal cells is apparent (Fig. $1 A$, asterisks).

The HCN1 isoform is also expressed in the pyramidal cell layer of the CA3 region of the immature rat hippocampus, in both pyramidal cells and interneurons (Figs. $1 A, C, 2 G, I$ ). The figures also demonstrate that in the P18 rat, CA3 interneuronal HCN1 expression exceeds the clearly visible pyramidal cell signal (Figs. $1 C, 2 H, I)$. This may be contrasted with the adult hippocampus, where HCN1 is not detectable in CA3 pyramidal cells (Santoro et al., 2000; Bender et al., 2001), indicating a strong developmental regulation of these channel genes.

HCN2 isoform expression is evident in CA1 and CA3 at both the mRNA and protein levels. Figure $1 D$ demonstrates a low magnification overview, delineating a rather homogenous HCN2 immunoreactivity in both subfields. This is in concordance with the comparable mRNA levels of HCN2 in CA1 and CA3 (see Fig. $4 B$ ). Higher-magnification views of CA1 (Fig. $1 E$ ) and CA3 (Fig. $1 F$ ), providing single-cell resolution, illustrate the higher HCN2 signal intensity in presumed interneuronal profiles. The in situ hybridization patterns (Fig. 2D,F,G,I) demonstrate HCN2 mRNA expression in pyramidal cells and in basket cells of both CA fields, in good agreement with the immunocytochemistry.

\section{The cellular HCN phenotype of individual CA1 and CA3 pyramidal cell layer neurons includes both HCN1 and HCN2}

If developmental seizures are to result in an altered cellular $\mathrm{HCN}$ phenotype of individual neurons within specific hippocampal cell populations, then coexpression of multiple isoforms leading to a repertoire of homomeric $\mathrm{HCN} 1$ and $\mathrm{HCN} 2$ channels within the individual cell should be demonstrable. Figure 2 shows double labeling for the two HCN isoforms within individual hippocampal CA1 and CA3 neurons. First, the expression of HCN1 mRNA in both parvalbumin-positive interneurons and parvalbuminlacking pyramidal cells is shown, using thin sections and confocal microscopy to avoid neuronal overlay (Fig. $2 A-C$ ). Next, combined ISH and ICC demonstrate the coexpression of HCN1 and HCN2 mRNA in individual CA1 neurons, highlighting the perinuclear mRNA aggregates (Fig. 2D, arrows) and the more peripheral distribution of the cytoplasmic protein signal (Fig. $2 E$, arrows, $F$, merged image). Coexpression of the two $\mathrm{HCN}$ isoforms (HCN2 mRNA and HCN1 protein) is also clearly apparent in individual CA3 pyramidal cell layer neurons (Fig. 2I, merged image). Thus, in the immature rat hippocampus, HCN1 and $\mathrm{HCN} 2$ are colocalized to individual pyramidal and interneuronal cells in the CA1 and CA3 pyramidal cell layers. Alteration of the expression of these isoforms by intense neuronal activity such as seizures should thus influence the cellular repertoire of HCNs, which are significantly governed at the mRNA level (Franz et al., 2000). In fact, such alteration in the properties of the current generated by these channels by prolonged experimental febrile seizures was demonstrated in previous electrophysiological studies of these seizures (K. Chen et al., 2001).

\section{Experimental febrile seizures lead to intense activation of the hippocampal circuit}

The hyperthermia procedure, as well as the administration of kainate, led to both electrophysiological and behavioral seizures 



Figure 1. Expression patterns of $\mathrm{HCN} 1$ and $\mathrm{HCN} 2$ immunoreactivity in the hippocampal formation of the immature rat. $A-C, \mathrm{HCN} 1 ; D-F, \mathrm{HCN} 2$. $A$, Low-magnification overview of HCN1 protein expression using immunocytochemistry, demonstrating this $\mathrm{HCN}$ isoform in the pyramidal cell layers of both CA1 and CA3. B, C, Detail of CA1 and CA3, respectively, demonstrating that the HCN1 isoform is expressed at the protein level in both pyramidal cells [arrows and insets; note the thick cytoplasmic band (boxed areas in $A$ ) of signal; see also Fig. 2] and interneurons (arrowheads). Note that in general, immunoreactivity in pyramidal cell somata is weaker than in interneurons, consistent with the distribution of channel proteins to the pyramidal cell dendritic fields (asterisks in $A$ ). $D$, Low-magnification view of HCN2 protein, revealing generally lower expression levels of this isoform. $E, F$, Detail of the CA1 and CA3 pyramidal cell layer (boxed areas in $D$ ), respectively, showing expression of the HCN2 isoform in individual eccentric, strongly labeled, presumed interneurons (arrowheads) as well as the much weaker expression in pyramidal cells (arrows and insets). Scale bars: $A$, $D$, 600 $\mu \mathrm{m} ; B, C, E, F, 200 \mu \mathrm{m}$; insets, $\sim 60 \mu \mathrm{m}$.

(Table 1; Fig. 3). As shown in Table 1, hyperthermia (defined as a core temperature of $>39^{\circ} \mathrm{C}$ ) led to seizures of $\sim 22.8 \mathrm{~min}$ duration. As described previously, these limbic seizures were characterized by a myoclonic jerk, which was followed by immobility associated with impaired ability to respond to stimuli and interspersed with limbic automatisms. The hippocampal electrographic (EEG) correlates of these seizures are shown in Figure $3 B$, demonstrating trains of spikes and spike waves with increasing amplitude emanating from the hippocampal electrodes. Administration of pentobarbital immediately before hyperthermia blocked both electrographic and behavioral seizures (Fig. 3, compare $C$ with $B$ ). The short-acting barbiturate reduced the amplitude of the baseline hippocampal EEG transiently, but in concordance with the behavior, the EEG of these hyperthermic controls normalized within $1 \mathrm{hr}$. It should be noted that the extent and duration of the hyperthermia per se did not differ between the hyperthermic controls and the group experiencing experimental febrile seizures. Hyperthermic controls thus served to distinguish the effects of hyperthermic (febrile) seizures from the potential effects of hyperthermia per se (Toth et al., 1998; Dubé et al., 2000). The short-acting barbiturate, the behavioral effects of which disappeared within $1 \mathrm{hr}$, was chosen to minimize or obviate potential neuroprotective effects.

Kainate resulted in hippocampal status epilepticus (i.e., electrographic and behavioral seizures lasting almost $3 \mathrm{hr}$ ) (Table 1; Fig. 3D). The behavioral manifestations of these seizures have been extensively described previously (Tremblay et al., 1984; Holmes et al., 1988; Brunson et al., 1998). Repetitive trains of high-amplitude spikes and spike waves, denoting electrographic seizures, are shown in Figure $3 D$. 

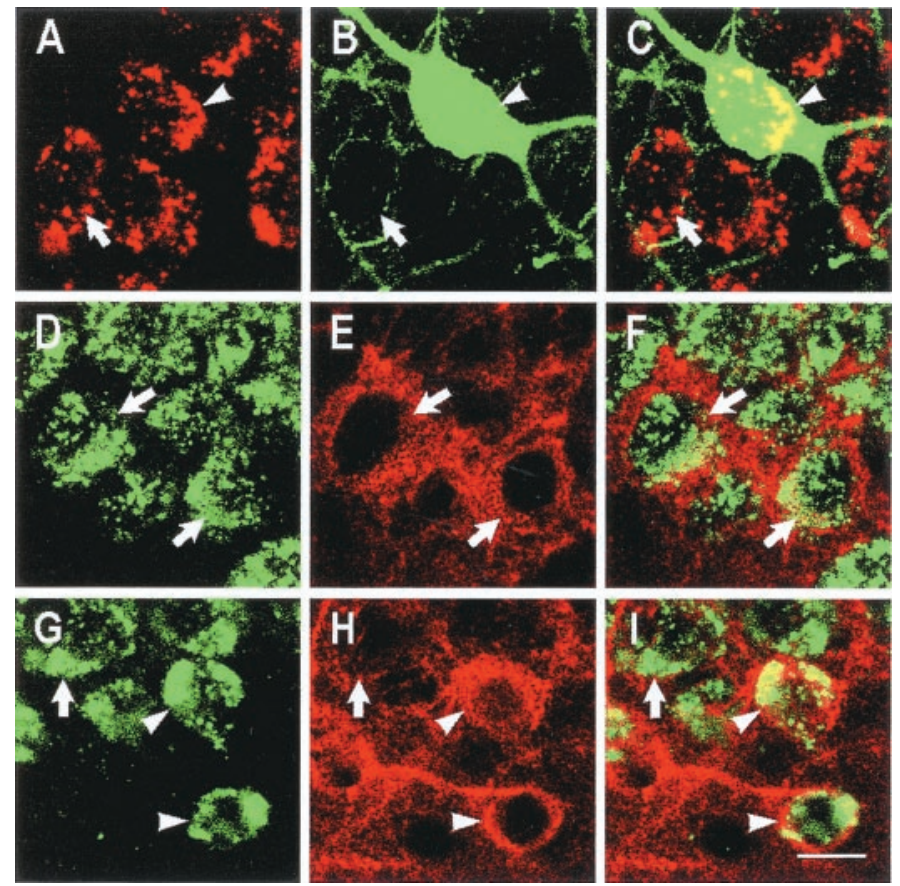

Figure 2. Individual hippocampal principal cells and interneurons coexpress $\mathrm{HCN} 1$ and $\mathrm{HCN} 2 . A-C$, Parvalbumin-expressing basket cells in hippocampal CA1 of the immature rat coexpress mRNA for HCN1 (HCN1 mRNA). A, ISH reveals expression of HCN1 mRNA in large neurons within the CA1 pyramidal cell layer (arrow and arrowhead). $B$, Parvalbumin ICC of the same section delineates a parvalbuminimmunoreactive interneuron (arrowhead) as well as the network of axonal boutons innervating parvalbumin-negative pyramidal neurons (arrows). $C$, The merged image of these confocal microscope sections (see Materials and Methods) demonstrates the coexpression of parvalbumin and HCN1 mRNA in the basket cell (arrowhead) as well as HCN1 expression in parvalbumin-negative presumed pyramidal cells (arrow). $D-F, \mathrm{HCN} 1$ protein is coexpressed with $\mathrm{HCN} 2$ in individual CA1 pyramidal cell layer neurons. $D$, ISH demonstrates $\mathrm{HCN} 2$ mRNA in the perinuclear cytoplasm of CA1 neurons (arrows). E, ICC demonstrates cytoplasmic HCN1 protein (arrows); the immunoreactivity pattern here, involving broad cytoplasmic patches, can be clearly distinguished from the delicate strands of parvalbumin-immunoreactive interneuronal processes (shown in $B$ ). $F$, The merged image reveals coexpression of both $\mathrm{HCN}$ isoforms in individual neurons (arrows), with mRNA generally confined to the perinuclear cytoplasm, versus the peripheral/membranous localization of the channel protein. $G-I$, Coexpression of $\mathrm{HCN} 1$ and $\mathrm{HCN} 2$ is also found in CA3. $G, \mathrm{HCN} 2$ mRNA; $H, \mathrm{HCN} 1$ protein; $I$, merged image. Scale bar, $20 \mu \mathrm{m}$.

\section{HCN expression is modulated by experimental prolonged febrile seizures with isoform and regional specificities}

Experimental febrile seizures resulted in alteration of $\mathrm{HCN}$ gene expression as measured using semiquantitative ISH (EghbalAhmadi et al., 1999; Brunson et al., 2001). Levels of HCN1 mRNA, encoding a fast activating and deactivating, lowconductance channel were significantly reduced in the CA1 pyramidal cell layer 1 week after the seizures. This effect was region-specific and not observed in $\mathrm{CA} 3$ (Fig. $4 A$ ). In contrast to this seizure-induced downregulation of $\mathrm{HCN} 1$, levels of $\mathrm{HCN} 2$ mRNA, encoding slower activating and deactivating channels, were increased. As shown in Figure $4 B$, experimental febrile seizures augmented $\mathrm{HCN} 2$ expression in both $\mathrm{CA} 1$ and $\mathrm{CA} 3$ pyramidal cell layers. The isoform specificity of this seizureinduced HCN modulation was also highlighted by the HCN4 data: seizures had no significant effect on this transcript in either

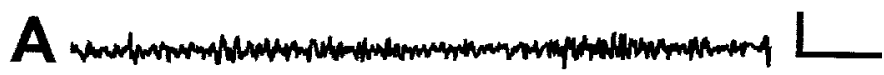


Figure 3. Hippocampal recordings of experimental febrile seizures and those generated by kainate. Tracings from bipolar, chronically implanted electrodes in behaving 11-d-old rats demonstrate normal background activity $(A) . B$, The hyperthermia procedure (see Materials and Methods) provoked hippocampal electrographic seizures, manifested as trains of spike waves. $C$, Preadministration of pentobarbital prevented these hyperthermia-induced seizures. $D$, Longer hippocampal electrographic seizures were induced by systemic administration of kainate. The evolution of increasing-amplitude spike-wave trains is seen. Calibration: 100 $\mu \mathrm{V}, 1 \mathrm{sec}$.

hippocampal field (Fig. 4C). The photomicrograph in Figure $4 C$ illustrates the unique expression of the HCN4 isoform in the medial habenula (Fig. 4C, asterisk) and the specificity of the ISH procedure (Bender et al., 2001). Thus, experimental febrile seizures reduced HCN1 expression and enhanced HCN2 mRNA levels in select hippocampal regions, without appreciable alteration of steady-state HCN4 mRNA.

\section{Seizures rather than hyperthermia per se alter HCN expression in a duration-dependent manner}

Experimental febrile seizures are generated by increasing the brain temperature of the immature rat (Toth et al., 1998; Dubé et al., 2000). To examine for the possibility that this hyperthermia in and of itself was required and sufficient to modulate $\mathrm{HCN}$ at the transcriptional level, we subjected a separate experimental animal group to identical duration and intensity of hyperthermia, while eliminating the seizures using a rapid-acting, short-duration barbiturate. As shown in Table 1, the hyperthermic stimulus did not differ between the seizure-experiencing and the hyperthermic control groups. However, eliminating the seizures (Fig. 3) abolished the alterations in HCN mRNA levels (Fig. 5). These findings indicate that hyperthermia per se is not sufficient to regulate $\mathrm{HCN}$ expression in the immature rat hippocampus.

To further delineate the role of synchronized neuronal firing (seizures) and to determine whether the consequences of such activity on $\mathrm{HCN}$ expression were unique to experimental febrile seizures, we induced prolonged seizures using the glutamate receptor agonist kainate (Tremblay et al., 1984; Holmes et al., 1988; Brunson et al., 1998). Similar to experimental febrile seizures, kainate resulted in intense hippocampal circuit activation, apparent from electrophysiological (Fig. 3) and behavioral (Brunson et al., 1998) measures. These seizures lasted $\sim 3 \mathrm{hr}$ compared with the shorter, $\sim 20$ min hyperthermia-induced activity (Table 1). 
A


B
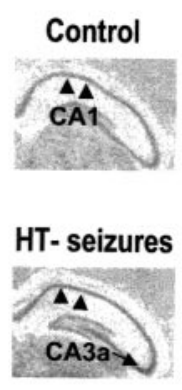

C

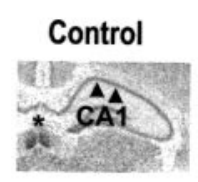

HT- seizures

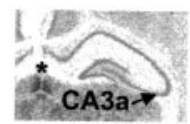


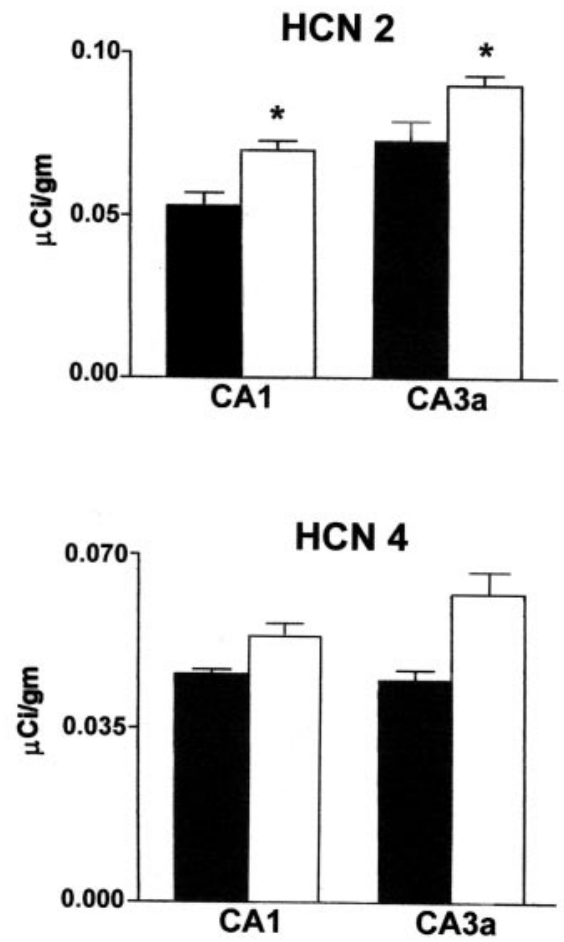

Figure 4. Experimental prolonged febrile seizures modulate the expression of HCN subunit isoform in a region- and isoform-specific manner. HCN mRNA levels were quantified after in situ hybridization analysis (see Materials and Methods). A, Compared with controls, HCN1 mRNA levels of experimental animals (HT-seizures) were significantly (asterisks) reduced in CA1 (arrowheads) but not CA3a. B, Levels of HCN2 mRNA, coding for slower-kinetics channels, were increased by the seizures in both CA1 and CA3 pyramidal cell layers. $C$, No significant changes in HCN4 mRNA levels were induced by the seizures. The asterisks in the photomicrograph denote the unique expression of the HCN4 isoform in the medial habenula.

Kainate-induced seizures influenced HCN isoform mRNA expression in a pattern concordant with the one resulting from experimental febrile seizures, and to a greater extent (Fig. 5; effect of seizure duration, $p<0.05$; one way ANOVA). These findings establish a dose effect for the duration of hippocampal seizures on HCN expression. In addition, they demonstrate that hyperthermia is not required for this activity-dependent regulation of $\mathrm{HCN}$ expression in immature rat hippocampal neurons.


Figure 5. The mechanism of HCN mRNA regulation requires seizures rather than hyperthermia and depends on seizure duration. Quantitative analyses of HCN1 and HCN2 mRNAs, to dissect out the contributions of the hyperthermia procedure versus those of the resulting seizures, are shown. $A, B, \mathrm{HCN} 1$ expression was reduced by hyperthermia-induced seizures (HT-seizures) in CA1 but not CA3. Blocking the seizures in a group of animals undergoing the same duration and magnitude of hyperthermia [pentobarbital and hyperthermia $(P B \& H T)$ group; Table 1] abolished these changes in HCN1. Longer seizures induced by kainate (Table 1) led to more robust modulation of $\mathrm{HCN} 1$ expression, also reducing mRNA levels in CA3. $C, D$, Enhanced $\mathrm{HCN} 2$ expression by hyperthermic seizures, found in both CA1 and CA3a pyramidal cell layers, required seizures (i.e., intense neuronal activation). This modulation of HCN expression was not specific to the experimental febrile seizures: prolonged kainate-induced seizures led to the same result. Correlation of HCN expression with seizure duration was found for both HCN1 $(A)$ and $\operatorname{HCN} 2(C, D)$ using ANOVA (see Results). *Significantly different from the control group. ${ }^{\dagger}$ SEMs of the control groups in $B$ $(0.54 \%)$ and $D(0.1 \%)$ are poorly visualized.

\section{Seizure-induced modulation of HCN expression is long-lasting}

The enhanced susceptibility to excitatory limbic stimuli induced by experimental febrile seizures in immature rats persisted through adulthood (Dubé et al., 2000). This was also the case for the functional alterations in $\mathrm{HCN}$ physiology after the seizures (K. Chen et al., 2001). The seizures may evoke transient alterations of HCN subunit expression, which are sufficient to activate "downstream" permanent changes in channel function. Alternatively, seizure-induced modulation of the expression of one or more $\mathrm{HCN}$ isoforms might be persistent, underlying functional changes in HCN currents and in hippocampal network excitability. As shown in Figure 6, reduced HCN1 expression in CA1 was still evident in adult rats that had experienced hyperthermic seizures early in life. The regional specificity of this modulation remained as well. It should be noted that the robust ISH signal of $\mathrm{HCN} 1$ in the CA3 pyramidal cell layer of these adult rats seems to be localized to interneurons (Santoro et al., 2000; Bender et al., 2001).

\section{DISCUSSION}

The major findings of these studies are: (1) During a critical developmental phase of hippocampal connectivity, HCN mRNA and protein are expressed in a highly isoform-specific and neuron-selective manner, and individual pyramidal cells and in- 


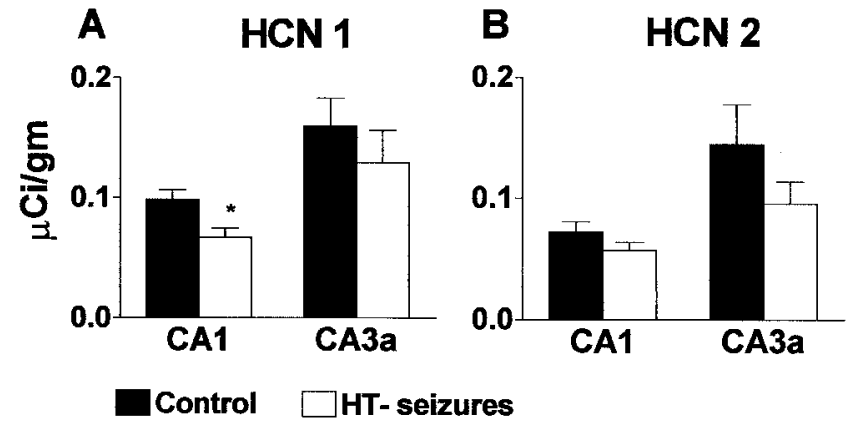

Figure 6. Changes in HCN1 expression induced by early life prolonged experimental febrile seizures are long lasting, whereas those in HCN2 are not. HCN mRNA levels were quantified after in situ hybridization analysis (see Materials and Methods) in animals 3 months after the seizures. $A$, Compared with controls, HCN1 mRNA levels of adult experimental animals (HT-seizures) were significantly (asterisk) reduced in CA1 but not CA3a. This is the same specific pattern found within 1 week of the seizures (Fig. 4A). Note that the high HCN1 mRNA signal over CA3 reflects interneuronal expression (Santoro et al., 2000; Bender et al., 2001): the resolution of the film autoradiograms does not permit distinguishing interneuronal expression (Brunson et al., 2001). B, Levels of HCN2 mRNA do not differ in CA1 or CA3 of adult control rats compared with those experiencing experimental febrile seizures early in life.

terneurons express multiple HCN subunit isoforms; (2) prolonged experimental febrile seizures reduce HCN1 mRNA and enhance HCN2 mRNA in specific hippocampal neuronal populations, and (3) the mechanisms of these long-lasting modulations require intense hippocampal circuit activity, in a durationdependent manner. Together with the previous demonstration of seizure-induced alteration of $\mathrm{HCN}$ function, these data indicate a novel isoform- and region-specific transcriptional regulation that modifies the HCN phenotype of specific hippocampal neuronal populations long term and is associated with profound consequences for the excitability of the hippocampal network.

The hyperpolarization-activated ion channels contribute to the maintenance of hippocampal neuronal membrane potential (Lupica et al., 2001) and to the slow depolarizing phase of at least some spontaneously firing hippocampal interneurons (Maccaferri and McBain, 1996). In vivo, the protein products of each of the four characterized $\mathrm{HCN}$ genes assemble to form homomeric channels (each comprised of four subunit molecules) with distinctive kinetics profiles and different regulation by cyclic nucleotides (Santoro and Tibbs, 1999).

In the hippocampus, the cellular HCN phenotype of pyramidal cells and interneurons is consistent with a major contribution of the HCN1 isoform (Franz et al., 2000; Santoro et al., 2000). This gene encodes channels with rapid activation and deactivation kinetics and limited conductance. Although HCN2 and HCN4, encoding channels with slower activation and deactivation kinetics, are expressed in both the mature and developing rodent hippocampus (Moosmang et al., 1999; Santoro et al., 2000; Bender et al., 2001), their contribution to the overall cellular HCN physiology of hippocampal neurons appears relatively minor. The findings here (Fig. 4), demonstrating higher mRNA expression levels of HCN1 compared with the other isoforms in the CA1 and CA3 of the immature rat hippocampus, provide a molecular basis for these observations and further support the notion that the functional HCN phenotype of individual neurons is governed significantly at the transcriptional level (Franz et al., 2000; Santoro et al., 2000).

A complex evolution of the spatiotemporal expression patterns of the HCNs takes place during hippocampal development, involving rapid, age-dependent, and isoform-specific changes in both hippocampal principal cells and interneurons (Bender et al., 2001). As shown here, multiple HCN isoforms are expressed in individual hippocampal neurons already during development, with distinct and differing time courses. These findings indicate that the HCN phenotype of specific hippocampal cell populations is developmentally regulated and suggest that at defined developmental phases, HCNs may play additional age-specific and cell-selective roles in the organization and synchronization of the hippocampal network.

Although the contribution of the HCNs to the organization and normal function of neuronal networks has been increasingly recognized (Pape, 1996; Santoro and Tibbs, 1999), the potential role of abnormal expression of HCNs in hippocampal pathology germane to human disease has only been emerging recently (K. Chen et al., 2001). Elimination or mutation of other ion channels may lead to hyperexcitable states, manifesting as spontaneous seizures (epilepsy) (Schroeder et al., 1998; Burgess and Noebels, 1999). In addition, inherited abnormalities in genes encoding several ion channels have been increasingly recognized as causal in several human inherited disorders. Specifically, these genetic "channelopathies," involving mutation in $\mathrm{Na}^{+}$(Wallace et al., 1998; Escayg et al., 2000) or $\mathrm{K}^{+}$(Biervert et al., 1998; Charlier et al., 1998; Zuberi et al., 1999) channels, underlie several human epilepsies. Previous electrophysiological studies implicated acquired, functional changes in the HCNs as causal in the proepileptogenic consequences of experimental febrile seizures on the hippocampal network (K. Chen et al., 2001). Here we show that these developmental seizures, as well as prolonged seizures induced by a chemical convulsant, modulate $\mathrm{HCN}$ molecule expression transcriptionally in a coordinated manner, favoring formation of such functionally modified HCNs.

The mechanisms of this seizure-induced regulation of $\mathrm{HCN}$ expression merit discussion. Transcriptional regulation of $\mathrm{HCN}$ gene expression has been described in the heart, governed by thyroid hormone (Pachucki et al., 1999). Because hyperthermia might influence thyroid hormone levels, the possibility that potential hyperthermia-induced changes in this hormone might contribute to the $\mathrm{HCN}$ expression changes shown here cannot be entirely excluded. However, hyperthermia per se, when the seizures were abolished, did not influence HCN expression significantly (Table 1; Fig. 5). In addition, prolonged, kainate-induced seizures without appreciable hyperthermia were sufficient to modulate HCN expression, demonstrating that hyperthermia was not a major determinant of this effect. Furthermore, the robust modulation of $\mathrm{HCN}$ expression by the prolonged ( $\sim 180 \mathrm{~min}$ ) kainate-induced seizures compared with the effects of the $\sim 20$ min, hyperthermia-induced activity supports the notion that hippocampal circuit activity, rather than hyperthermia, might be the key mechanism for this novel regulation of $\mathrm{HCN}$ expression in the immature rat hippocampus.

The precise chain of events by which alterations of $\mathrm{HCN}$ expression and function result in proepileptogenic effects on immature hippocampus requires additional study. As mentioned above, the HCN phenotype of normal hippocampal pyramidal cells reflects a preponderance of HCN1 channels. These might actually contribute to attenuating the impact of dendritic excitatory input on pyramidal cell firing (Poolos and Johnston, 2001). However, the seizure-induced modification of HCN expression patterns shown here favors increased abundance of slowerkinetics (potentially larger conductance) HCN2 channels in af- 
fected neurons, promoting neuronal activity-dependent depolarization and firing (K. Chen et al., 2001) and enhancing excitation in the hippocampal circuit.

It is considered that although the long-term modulation of HCN expression might critically contribute to the augmented hippocampal excitability and the susceptibility to additional seizures that were found after experimental febrile seizures, the regulation of HCNs is likely not the sole mechanisms for such changes. First, developmental experimental febrile seizures lead to other proexcitatory changes in the hippocampal network such as synaptic reorganization (Bender et al., 2000) and alteration of glutamate receptor-mediated calcium permeability (EghbalAhmadi et al., 2001). In addition, HCN gene modulation was also found after very prolonged developmental seizures induced by kainate (Fig. 5). Although these seizures (during the developmental age discussed here) have not been shown to be proepileptogenic, they do cause significant changes in the function of the hippocampal network, manifested by long-lasting impairment of hippocampal-dependent learning and memory performance (Holmes et al., 1988; Stafstrom et al., 1993; Lynch et al., 2000, but see Sarkisian et al., 1997). Whether the robust alterations of HCN expression patterns after kainate-induced seizures contribute to these functional changes should be a focus of further studies.

The persistence of the seizure-induced changes in expression of the HCN1 subunit after relatively short developmental seizures is striking. Work from several laboratories has demonstrated short-lived alterations in several genes that contribute to the regulation of hippocampal excitability after seizures occurring during the first two postnatal weeks in the rat (Friedman et al., 1997; Hatalski et al., 2000; Sanchez et al., 2001). However, the current data indicate that developmental seizures may leave permanent marks on the repertoire of hippocampal gene expression, with implications for hippocampal excitability. Clearly, the final effect, in terms of susceptibility to additional seizures or the development of frank spontaneous seizures (epilepsy), would be a complex product of these and other independent or compensatory changes in the network (Chen et al., 1999; Walker and Kullmann, 1999). Finally, whether these changes also happen in humans remains speculative, and whether early life seizures, generally considered benign, modify the human hippocampus long term in a subtle manner remains to be investigated.

In summary, the current studies demonstrate that developmental seizures modify hippocampal $\mathrm{HCN}$ expression at the transcriptional level in a highly isoform- and cell-specific manner. This constitutes a novel, activity-dependent regulation of these genes in the CNS. Importantly, these studies provide an additional perspective to the complexity of the mechanisms by which early life seizures influence hippocampal function long term.

Note added in proof. The report by Brauer et al. (2001), describing transient reduction of hippocampal $\mathrm{HCN} 1$, was published after submission of this work.

\section{REFERENCES}

Baram TZ, Hatalski CG (1998) Neuropeptide-mediated excitability: a key triggering mechanism for seizure generation in the developing brain. Trends Neurosci 21:471-476.

Bender RA, Baram TZ (2002) Do prolonged febrile seizures injure hippocampal neurons? Insights from animal models. In: Febrile seizures (Baram TZ, Shinnar S, eds), pp 127-137. San Diego: Academic.

Bender RA, Dubé C, Baram TZ (2000) Mossy fiber sprouting into the inner molecular layer of the dentate gyrus follows prolonged febrile seizures in the immature rat model. Epilepsia 41 [Suppl 7]:76.

Bender RA, Brewster A, Santoro B, Ludwig A, Hofmann F, Biel M, Baram TZ (2001) Differential and age-dependent expression of hyperpolarization-activated, cyclic nucleotide-gated cation channel iso- forms 1-4 suggests evolving roles in the developing rat hippocampus. Neuroscience 106:689-698.

Biervert C, Schroeder BC, Kubisch C, Berkovic SF, Propping P, Jentsch TJ, Steinlein OK (1998) A potassium channel mutation in neonatal human epilepsy. Science 279:403-406.

Brauer AU, Savaskan NE, Kole MH, Plaschke M, Monteggia LM, Nestler EJ, Simburger E, Deisz RA, Ninneman O, Nitsch R (2001) Molecular and functional analysis of hyperpolarization-activated pacemaker channels in the hippocampus after entorhinal cortex lesion. FASEB J 15:2689-2701.

Brunson KL, Schultz L, Baram TZ (1998) The in vivo proconvulsant effects of corticotropin releasing hormone in the developing rat are independent of ionotropic glutamate receptor activation. Brain Res Dev Brain Res 111:119-128.

Brunson KL, Eghbal-Ahmadi M, Bender RA, Chen Y, Baram TZ (2001) Long-term, progressive hippocampal cell loss and dysfunction induced by early-life administration of corticotropin-releasing hormone reproduce the effects of early-life stress. Proc Natl Acad Sci USA 98:8856-8861.

Burgess DL, Noebels JL (1999) Voltage-dependent calcium channel mutations in neurological disease. Ann NY Acad Sci 868:199-212.

Cendes F, Andermann F (2002) Do febrile seizures promote temporal lobe epilepsy? Retrospective studies. In: Febrile seizures (Baram TZ, Shinnar S, eds), pp 77-86. San Diego: Academic.

Charlier C, Singh NA, Ryan SG, Lewis TB, Reus BE, Leach RJ, Leppert M (1998) A pore mutation in a novel KQT-like potassium channel gene in an idiopathic epilepsy family. Nat Genet 18:53-55.

Chen K, Baram TZ, Soltesz I (1999) Febrile seizures in the developing brain result in persistent modification of neuronal excitability in limbic circuits. Nat Med 5:888-894.

Chen K, Aradi I, Thon N, Eghbal-Ahmadi M, Baram TZ, Soltesz I (2001) Persistently modified h-channels after complex febrile seizures convert the seizure-induced enhancement of inhibition to hyperexcitability. Nat Med 7:331-337.

Chen S, Wang J, Siegelbaum SA (2001) Properties of hyperpolarizationactivated pacemaker current defined by coassembly of HCN1 and HCN2 subunits and basal modulation by cyclic nucleotide. J Gen Physiol 117:491-503.

Chen Y, Bender RA, Frotscher M, Baram TZ (2001) Novel and transient populations of corticotropin-releasing hormone-expressing neurons in developing hippocampus suggest unique functional roles: a quantitative spatiotemporal analysis. J Neurosci 21:7171-7181.

DiFrancesco D (1993) Pacemaker mechanisms in cardiac tissue. Annu Rev Physiol 55:455-472.

DiFrancesco D, Tortora P (1991) Direct activation of cardiac pacemaker channels by intracellular cyclic AMP. Nature 351:145-147.

Dubé C (2002) Do prolonged febrile seizures in an immature rat model cause epilepsy? In: Febrile seizures (Baram TZ, Shinnar S, eds), pp 215-229. San Diego: Academic.

Dubé C, Chen K, Eghbal-Ahmadi M, Brunson K, Soltesz I, Baram TZ (2000) Prolonged febrile seizures in the immature rat model enhance hippocampal excitability long term. Ann Neurol 47:336-344.

Eghbal-Ahmadi M, Avishai-Eliner S, Hatalski CG, Baram TZ (1999) Differential regulation of the expression of corticotropin-releasing factor receptor type $2\left(\mathrm{CRF}_{2}\right)$ in hypothalamus and amygdala of the immature rat by sensory input and food intake. J Neurosci 19:3982-3991

Eghbal-Ahmadi M, Yin H, Stafstrom CE, Tran K, Weiss JH, Baram TZ (2001) Altered expression of specific AMPA type glutamate receptor subunits after prolonged experimental febrile seizures in CA3 of immature rat hippocampus. Soc Neurosci Abstr 31:684.6.

Escayg A, MacDonald BT, Meisler MH, Baulac S, Huberfeld G, AnGourfinkel I, Brice A, LeGuern E, Moulard B, Chaigne D, Buresi C, Malafosse A (2000) Mutations of SCN1A, encoding a neuronal sodium channel, in two families with GEFS +2. Nat Genet 24:343-345.

Franz O, Liss B, Neu A, Roeper J (2000) Single-cell mRNA expression of HCN1 correlates with a fast gating phenotype of hyperpolarizationactivated cyclic nucleotide-gated ion channels (Ih) in central neurons. Eur J Neurosci 12:2685-2693.

Friedman LK, Sperber EF, Moshe SL, Bennett MV, Zukin RS (1997) Developmental regulation of glutamate and GABA(A) receptor gene expression in rat hippocampus following kainate-induced status epilepticus. Dev Neurosci 19:529-542.

Gauss R, Seifert R, Kaupp UB (1998) Molecular identification of a hyperpolarization-activated channel in sea urchin sperm. Nature 393:583-587.

Gottlieb A, Keydar I, Epstein HT (1977) Rodent brain growth stages: an analytical review. Biol Neonate 32:166-176.

Hatalski CG, Brunson KL, Tantayanubutr B, Chen Y, Baram TZ (2000) Neuronal activity and stress differently regulate hippocampal and hypothalamic corticotropin-releasing hormone expression in the immature rat. Neuroscience 101:571-580.

Hauser WA (1994) The prevalence and incidence of convulsive disorders in children. Epilepsia 35 [Suppl 2]:S1-S6. 
Herschkowitz N, Kagan J, Zilles K (1997) Neurobiological bases of behavioral development in the first year. Neuropediatrics 28:296-306.

Holmes GL, Thompson JL, Marchi T, Feldman DS (1988) Behavioral effects of kainic acid administration on the immature brain. Epilepsia 29:721-730.

Hunyady B, Krempels K, Harta G, Mezey É (1996) Immunohistochemical signal amplification by catalyzed reporter deposition and its application in double immunostaining. $\mathrm{J}$ Histochem Cytochem 44:1353-1362.

Ishii TM, Takano M, Xie LH, Noma A, Ohmori H (1999) Molecular characterization of the hyperpolarization-activated cation channel in rabbit heart sinoatrial node. J Biol Chem 274:12835-12839.

Ludwig A, Zong X, Jeglitsch M, Hofmann F, Biel M (1998) A family of hyperpolarization-activated mammalian cation channels. Nature 393:587-591.

Lupica CR, Bell JA, Hoffman AF, Watson PL (2001) Contribution of the hyperpolarization-activated current $\left(I_{\mathrm{h}}\right)$ to membrane potential and GABA release in hippocampal interneurons. $J$ Neurophysiol $86: 261-268$.

Lynch M, Sayin Ü, Bownds J, Janumpalli S, Sutula T (2000) Long-term consequences of early postnatal seizures on hippocampal learning and plasticity. Eur J Neurosci 12:2252-2264.

Maccaferri G, McBain CJ (1996) The hyperpolarization-activated current $\left(I_{\mathrm{b}}\right)$ and its contribution to pacemaker activity in rat CA1 hippocampal stratum oriens-alveus interneurons. J Physiol (Lond) 497:119-130

Monteggia LM, Eisch AJ, Tang MD, Kaczmarek LK, Nestler EJ (2000) Cloning and localization of the hyperpolarization-activated cyclic nucleotide-gated channel family in rat brain. Brain Res Mol Brain Res $81: 129-139$.

Moosmang S, Biel M, Hofmann F, Ludwig A (1999) Differential distribution of four hyperpolarization-activated cation channels in mouse brains. Biol Chem 380:975-980.

Pachucki J, Burmeister LA, Larsen PR (1999) Thyroid hormone regulates hyperpolarization-activated cyclic nucleotide-gated channel (HCN2) mRNA in the rat heart. Circ Res 85:498-503.

Pape HC (1996) Queer current and pacemaker: the hyperpolarizationactivated cation current in neurons. Annu Rev Physiol 58:299-327.

Poolos NP, Johnston D (2001) A novel anticonvulsant decreases the excitability of dendrites in hippocampal neurons by increasing the activation of $\mathrm{I}_{\mathrm{H}}$. Soc Neurosci Abstr 31:605.2.

Sanchez RM, Koh S, Rio C, Wang C, Lamperti ED, Sharma D, Corfas G, Jensen FE (2001) Decreased glutamate receptor 2 expression and enhanced epileptogenesis in immature rat hippocampus after perinatal hypoxia-induced seizures. J Neurosci 21:8154-8163.

Santoro B, Tibbs GR (1999) The HCN gene family: molecular basis of the hyperpolarization-activated pacemaker channels. Ann NY Acad Sci 868:741-764.
Santoro B, Grant SGN, Bartsch D, Kandel ER (1997) Interactive cloning with the $\mathrm{SH} 3$ domain of N-src identifies a new brain specific ion channel protein, with homology to Eag and cyclic nucleotide-gated channels. Proc Natl Acad Sci USA 94:14815-14820.

Santoro B, Liu D, Yao H, Bartsch D, Kandel ER, Siegelbaum SA, Tibbs GR (1998) Identification of a gene encoding a hyperpolarizationactivated pacemaker channel of brain. Cell 93:717-729.

Santoro B, Chen S, Lüthi A, Pavlidis P, Shumyatsky GP, Tibbs GR, Siegelbaum SA (2000) Molecular and functional heterogeneity of hyperpolarization-activated pacemaker channels in the mouse CNS. J Neurosci 20:5264-5275.

Sarkisian MR, Tandon P, Liu Z, Yang Y, Hori A, Holmes GL, Stafstrom CE (1997) Multiple kainic acid seizures in the immature and adult brain: ictal manifestations and long-term effects on learning and memory. Epilepsia 38:1157-1166.

Schroeder BC, Kubisch C, Stein V, Jentsch TJ (1998) Moderate loss of function of cyclic-AMP-modulated KCNQ2/KCNQ3 K+ channels causes epilepsy. Nature 396:687-690.

Shinnar S (1998) Prolonged febrile seizures and mesial temporal sclerosis. Ann Neurol 43:411-412.

Stafstrom CE, Chronopoulos A, Thurber S, Thompson JL, Holmes GL (1993) Age-dependent cognitive and behavioral deficits after kainic acid seizures. Epilepsia 34:420-432.

Toth Z, Yan XX, Haftoglou S, Ribak CE, Baram TZ (1998) Seizureinduced neuronal injury: vulnerability to febrile seizures in an immature rat model. J Neurosci 18:4285-4294.

Tremblay E, Nitecka L, Berger ML, Ben-Ari Y (1984) Maturation of kainic acid seizure-brain damage syndrome in the rat. I. Clinical, electrographic and metabolic observations. Neuroscience 13:1051-1072.

Ulens C, Tytgat J (2001) Functional heteromerization of HCN1 and HCN2 pacemaker channels. J Biol Chem 276:6069-6072.

Waigner BJ, DeGennaro M, Santoro B, Siegelbaum SA, Tibbs GR (2001) Molecular mechanism of cAMP modulation of $\mathrm{HCN}$ pacemaker channels. Nature 411:805-809.

Walker MC, Kullmann DM (1999) Febrile convulsions: a "benign" condition? Nat Med 5:871-872.

Wallace RH, Wang DW, Singh R, Scheffer IE, George Jr AL, Phillips HA, Saar K, Reis A, Johnson EW, Sutherland GR, Berkovic SF, Mulley JC (1998) Febrile seizures and generalized epilepsy associated with a mutation in the $\mathrm{Na}+$-channel $\beta 1$ subunit gene $\mathrm{SCN} 1 \mathrm{~B}$. Nat Genet 19:366-370

Zuberi SM, Eunson LH, Spauschus A, De Silva R, Tolmie J, Wood NW, McWilliam RC, Stephenson JP, Kullmann DM, Hanna MG (1999) A novel mutation in the human voltage-gated potassium channel gene (Kv1.1) associates with episodic ataxia type 1 and sometimes with partial epilepsy. Brain 122:817-825. 